\title{
Strategies Used in Translation of English Idioms into Persian in Novels
}

\author{
Shokooh Khosravi \\ Science and Research Branch, Islamic Azad University, Tehran, Iran \\ Email: glorykhosravi@yahoo.com \\ Mohammad Khatib \\ Allameh Tabataba'i University, Tehran, Iran \\ Email: mkhatib27@yahoo.com
}

\begin{abstract}
The present study aimed to focus mainly on the investigation of the strategies used for English into Persian translation of idioms and idiomatic expressions in the novels of "To kill a mockingbird" by Harper Lee and "Of mice and men" by John Steinbeck. This research is done based on Baker's model for translating, namely, using her four strategies for translating idioms, i.e., using an idiom of similar meaning and form, using an idiom of similar meaning but dissimilar form, translation by paraphrase, and translation by omission. The researcher wanted to find out which strategy was the most frequently used strategy and whether there were any significant differences among the uses of these strategies. Conducting a descriptive statistical analysis, it has been concluded that 'paraphrase' and 'using an idiom of similar meaning and form' were the most and the least common strategies, with the frequencies of 290 and 9 , and percentages of $71.25 \%$ and $2.21 \%$, respectively. On the basis of the findings of this research, it is recommended that, in addition of having enough knowledge in terms of the theoretical translation issues and the translation strategies suggested by different scholars, a translator should have a good command of the TL idiomatic expressions, and in the case of translating novels, benefit from the required creativity to handle the challenging task of transferring the idiom into the TL.
\end{abstract}

Index Terms - translation strategy, idioms, novel

\section{INTRODUCTION}

All languages have phrases and sentences that cannot be understood literally. Knowing a language includes knowing the morphemes, simple words, compound words, and their meanings. It also means knowing fixed phrases, consisting of more than one word, with meanings that cannot be inferred from the meanings of the individual words. Even if we know the meaning of all the words in a phrase and understand the grammar completely, the total meaning of the phrase may still be confusing. Many idioms offer this kind of problem and all languages contain many such expressions. A phrase and sentence of this type is said to be idiomatic. Idioms are similar in structure to ordinary phrases except that they tend to be frozen in form and do not readily enter into other combinations or allow the word order to change. Idioms and idiomaticity are pervasive features of a language. English has many thousands of such idiomatic expressions, which are suitable for expressing speaker's intentions in different situations. Idiomatic expressions play role in the construction of interpersonal meanings, in the formation of coherent text, and in the creation of stylistic effects. Fernando demonstrates the bipolar nature of idiomaticity in the balance between routinized expression and linguistic creativity (Fernando, 1996, p. xvii).

People may not have a true understanding of the meaning of an idiom "since the true meaning of an idiom generally cannot be determined by a knowledge of its constituent parts" (Collis, 1994, p. v).

\section{A. Background of the Problem}

As the phenomenon of translation is an intercultural activity, so the TL that takes the information is influenced unbelievably. The translators involved in translating might not sometimes be cognizant of the sensitivity and complication of their task. Translating idioms is a crucial issue in literary translation; sometimes it either leads to the increase of cultural gaps or it doesn't let these gaps to be filled.

\section{B. Significance of the Study}

Idiomatic expressions are culture-specific items. It is of importance to know how professional translators render them. Many believe that they cannot be translated literally and can be substituted by a similar idiom in the target culture. According to Armellino (2003), one of the most challenging tasks for all translators is rendering culture-bound elements. As he states in his article, the reasons for this point is always strongly linked to the specific culture context where the text originates or with the cultural context it aims to recreate. 
Ghaffari (2001) believed that "without using idioms, the language becomes harsh and unattractive, so it can be said the words are like a skeleton of the language and the idioms are like its soul. Therefore, wrong translation of idioms may damage the soul of the language" (p. 2).

Considering the point that idiom is a problematic item for translation, this study seeks answer to the following question:

- Which of Baker's strategies (1992) are most frequently used in translating idioms in the novels (To kill a mockingbird and Of mice and men)?

\section{Definition of Key Terms}

Translation strategy: Translation strategy refers to "a conscious procedure for the solution of a problem which an individual is faced with when translating a text segment from one language to another" (Lörscher, 1991, p. 76, as cited in Chesterman, 2005).

Idioms: Idioms are frozen patterns of language which allow little or no variation in form and often carry meanings which cannot be deduced from their individual components. Idioms do not have flexibility of patterning and transparency of meaning. (Baker, 1992, p. 63)

Novel: Novel is now applied to a great variety of writings that have in common only the attribute of being extended works of fiction written in prose. As an extended narrative, the novel is distinguished from the short story and from the work of middle length called the novelette (M.H. Abrams, 1993, p. 190).

\section{Types of Idioms}

Idioms may have different forms. In their book, Seidl and McMordie (1988, p. 13) distinguish 3 types of idioms:

1. Form irregular, meaning clear, as in give someone to understand

2. Form regular, meaning unclear, as in cut no ice

3. Form irregular, meaning unclear, as in go great guns

\section{E. Characteristics of Idioms}

Linguists have suggested different characteristics for idioms, which are generally based, according to Stock (1989, p.9), "on two basic points of view: one point of view considers idioms as the basic units of language, with holistic characteristics", and the other point of view that emphasizes on the definite role in the complete idiom".

1. Lexical and syntactic flexibility

"A limited number of idioms have one (or more) lexical variants. However, most are lexically fixed (nonproductive) to a large extent. Analyzable (less idiomatic) expressions are often more open to lexical substitution and syntactic variation" (Fazly and Stevenson, 2006, p.2).

2. Transparency

"Transparency (or semantic analyzability) refers to the degree of agreement between the literal and figurative meanings of an idiom" (Cain, Oak hill and Lemmon, 2004, p.3).

3. Idiom familiarity

It has been defined by Nippold and Taylor (1995, p. 427, as cited in Cain, Oak hill and Lemmon, 2004, p. 2) as "how frequently an idiom occurs in the language. Children, adolescents, and adults find that more familiar idioms are easier to understand than less familiar ones".

4. Non-compositionality

"The meaning of an idiom is typically not predictable from those of its parts, as in the often cited example kick the bucket (die). In contrast, spill the beans is decomposable into its parts with beans modeling a secret and spill is revelation" (Chang \& Fischer, 2006, p.1).

5. Syntactic modifications

Chang \& Fischer (2006, p.1) claim "Many idioms are lexically specific and do not permit substitution of even close synonyms". But, they further add "even idioms with fixed lexical items often appear in syntactically diverse forms" (ibid, p.1).

6. Opacity

"Idioms such as by and large and spick and span are often considered opaque: the semantic motivation or source for the idiom may be unclear, and no particular underlying image may come to mind" (ibid, p.1).

Chang \& Fischer (ibid, p.1) finally conclude "In their central (or prototypical) case, idioms are non-compositional, lexically simple and opaque; they have some constituents and have some literal reading and allow only limited syntactic variations".

\section{F. Culture Specific Terms}

As it is clear from their name, these terms usually belong to a specific culture and are unknown for the people having another culture. Idioms are found in all languages. Yet some types of idioms are more prominent in one language than in another, and they may be culture-specific (Boers, 2000a). Thus, culture should not be neglected in the discussion of the use of idioms. Research has shown that most figurative idioms (arguably the largest type of idioms) are metaphorically based and conceptually motivated. A metaphorical concept that is noticeable in one culture may, 
however, be relatively inconspicuous in another, due to cultural differences. Schwarz (2003, p.1) confirms that "Although more and more concepts are shared and understood between different cultures, there are still many terms and expressions which reflect the morals and values of a particular culture and have no true equivalent in the TL". She also suggests "to deal with these cultural terms successfully, a translator has to be not only bilingual but also bi-cultural. There are two main strategies when dealing with cultural frames and they are known as domestication and foreignization". She borrows these terms from Venuti (1995, p.47) who points out that "all translation is fundamentally domestication and is really initiated in the domestic culture". The idea of 'foreignizing a translation' was introduced by Venuti $(1995$, p.4) and he defines this process as "taking the reader over to the foreign culture, making him or her see the (cultural and linguistic) differences".

"Newmark (1993) points out that slang and idioms are closely linked to culture and a particular period" (cited in Schwarz, 2003, p.77).

\section{G. Difficulties of Translation of Idioms}

Once an idiom has been recognized and interpreted correctly, the next step is to decide how to translate it into the TL. The difficulties involved in translating an idiom are totally different from those involved in interpreting it. Here, the question is not whether a given idiom is transparent, opaque, or misleading. An opaque expression may be easier to translate than a transparent one.

Baker (1992) asserts that the main problems posed by idiomatic and fixed expressions for translators relate to two principal areas: "The ability to recognize and interpret an idiom correctly; and the difficulties involved in rendering the various aspects of meaning that an idiom or a fixed expression conveys into the TL" (p. 65).

She also mentions, "The first difficulty that a translator comes across in being able to recognize that s/he is dealing with an idiomatic expression" (1992, p.6). She further states "the more difficult an expression is to understand and the less sense it makes in a given context, the more likely a translator will recognize it as an idiom” (ibid, p.65).

The main difficulties involved in translating idioms are summarized by Baker (1992, pp.68-71) as follows:

(a) An idiom or fixed expression may have no equivalent in the TL.

(b) An idiom or fixed expression may have a similar counterpart in the TL, but its context of use may be different; the two expressions may have different connotations or they may not be pragmatically transferable.

(c) An idiom may be used in the ST in both its literal and idiomatic senses at the same time. Unless the TL idiom corresponds to the SL idiom both in form and in meaning, the play on idiom cannot be successfully reproduced in the TT.

(d) The very convention of using idioms in written discourse, the contexts in which they can be used and their frequency of use may be different in the source and target languages.

\section{H. Strategies for Translating Idioms}

The way in which an idiom or a fixed expression can be translated into another language depends on many factors. It is not only a question of whether an idiom with a similar meaning is available in the TL. Other factors include, for example, the significance of the specific lexical items which constitute the idiom, i.e. whether they are manipulated elsewhere in the ST, as well as the appropriateness or inappropriateness of using idiomatic language in a given register in the TL. The acceptability or non-acceptability of using any of the strategies described below will therefore depend on the context in which a given idiom is translated. The first strategy described, that of finding an idiom of similar meaning and similar form in the TL, may seem to offer the ideal solution, but that is not necessarily always the case. Questions of style, register, and rhetorical effect, must also be taken into consideration. Fernando and Flavell are correct in warning us against the 'strong unconscious urge in most translators to search hard for an idiom in the receptor-language, however inappropriate it may be' (1981, p. 82, as cited in Baker, 1992, p. 72).

Baker (1992, p. 72-78) suggests the following strategies for translating idioms:

(1) Using an idiom of similar meaning and form

This strategy involves using an idiom in the TL which conveys roughly the same meaning as that of the sourcelanguage idiom and, in addition, consists of equivalent lexical items. This kind of match can only occasionally be achieved.

(2) Using an idiom of similar meaning but dissimilar form

It is often possible to find an idiom or fixed expression in the target language which has a meaning similar to that of the source idiom or expression, but which consists of different lexical items.

\section{(3) Translation by paraphrase}

This is by far the most common way of translating idioms when a match cannot be found in the TL or when it seems inappropriate to use idiomatic language in the TT because of differences in stylistic preferences of the source and target languages.

\section{(4) Translation by omission}

As with single words, an idiom may sometimes be omitted altogether in the TT. This may be because it has no close match in the TL, its meaning cannot be easily paraphrased, or for stylistic reasons.

\section{Methodology}


This research is carried out within the framework of descriptive approach of the comparative model of translation research and uses a parallel-corpus. The researcher's approach is non-judgmental and non-evaluative, thus the translations of the idioms are considered as acceptable and appropriate and all the possible misspellings and wrong translations are not going to be considered.

The researcher chose whole pages of the novels listed below for doing this research:

$$
\begin{aligned}
& \text { To kill a mockingbird by: Harper Lee } \\
& \text { Of mice and men by: John Steinbeck }
\end{aligned}
$$

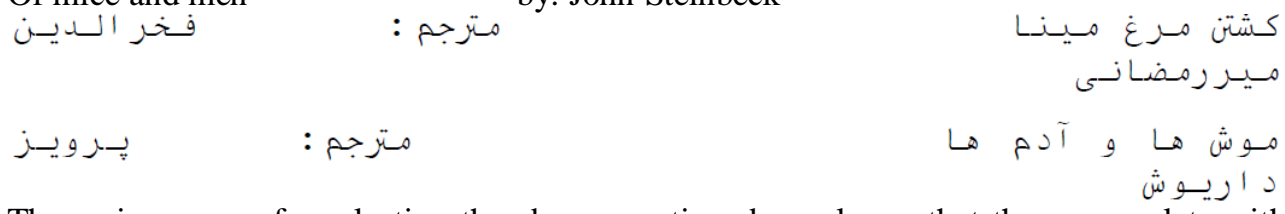

The main reasons for selecting the above-mentioned novels are that they are replete with idioms, written by wellknown writers, and they are among the bestselling novels and famous both for English and Persian readers.

After reading the English novels and selecting the sentences that contained idioms, the Persian translations were read. Then, the researcher compared the English texts with the Persian translations side by side in order to determine which of Baker's strategies are more frequently used by the translators. After collecting and tabulating the data for each novel, in order to find the frequency of the strategies employed for the translation of idioms in the selected novels, the obtained data from all the selected novels were shown in a separate table. It can be concluded from this table that which strategy is dominant in translating idioms in novels from English to Persian.

\section{DATA ANALYSIS AND DiSCUSSION}

In the process of data analysis, two English novels and their Persian translations were selected as the corpus of study. The analysis has been carried out on 407 idiomatic expressions extracted from these two novels. For each novel, the researcher has prepared two separate tables representing the procedure of data analysis. The first table provides the sentences of the novels which contained the selected idiomatic expressions. In the second table the comparison of each idiomatic expression with its Persian equivalent and the related translation strategy will be represented.

TABLE 1:

\begin{tabular}{|c|c|c|}
\hline English idioms & Persian translations & Applied strategy \\
\hline Tooth and nail & إن جإنى و دندان & Using an idiom of similar meaning and form \\
\hline Acid tongue in her head & زبان نيشدارى داشت. & $\begin{array}{l}\text { Using an idiom of similar meaning but } \\
\text { dissimilar form }\end{array}$ \\
\hline On tenterhooks & مثل اينكه روى تاوه ى آتش باشم. & Translation by paraphrase \\
\hline To scrape a few barnacles off the ship of state & 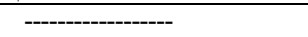 & Translation by omission \\
\hline
\end{tabular}

SENTENCES AND THEIR TRANSLATION IN "TO KILL A MOCKINGBIRD”

TABLE 2:

PerCentage OF EACH STRATEGY IN “TO KILl A MOCKINGBiRD”

\begin{tabular}{|l|l|l|}
\hline Strategies & Frequency & Percentage \\
\hline Using an idiom of similar meaning and form & 5 & $16.66 \%$ \\
\hline Using an idiom of similar meaning but dissimilar form & 8 & $26.66 \%$ \\
\hline Translation by paraphrase & 16 & $53.33 \%$ \\
\hline Translation by omission & 1 & $3.33 \%$ \\
\hline Total & 30 & $100 \%$ \\
\hline
\end{tabular}

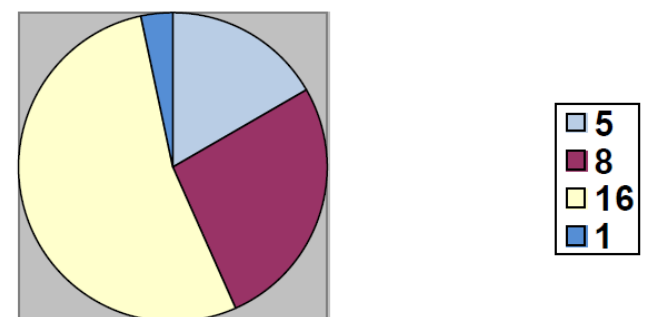

Figure 1: Percentage of each strategy To Kill a Mockingbird

TABLE 3:

\begin{tabular}{|c|c|c|}
\hline English idioms & Persian translations & Applied strategy \\
\hline Rattrap & ا تله موش & Using an idiom of similar meaning and form \\
\hline In hot water & (2) & Using an idiom of similar meaning but dissimilar form \\
\hline Right cross & با دس ر اسش اينجور كثيده زده & Translation by paraphrase \\
\hline
\end{tabular}

SENTENCES AND THEIR TRANSLATION IN “OF MICE AND MEN" 
TABLE 4:

PeRCENTAGE OF EACH STRATEGY IN “OF MiCE AND MEN"

\begin{tabular}{|l|l|l|}
\hline Strategies & Frequency & Percentage \\
\hline Using an idiom of similar meaning and form & 4 & $1.06 \%$ \\
\hline Using an idiom of similar meaning but dissimilar form & 66 & $17.50 \%$ \\
\hline Translation by paraphrase & 274 & $72.67 \%$ \\
\hline Translation by omission & 33 & $8.75 \%$ \\
\hline Total & 377 & 100 \\
\hline
\end{tabular}
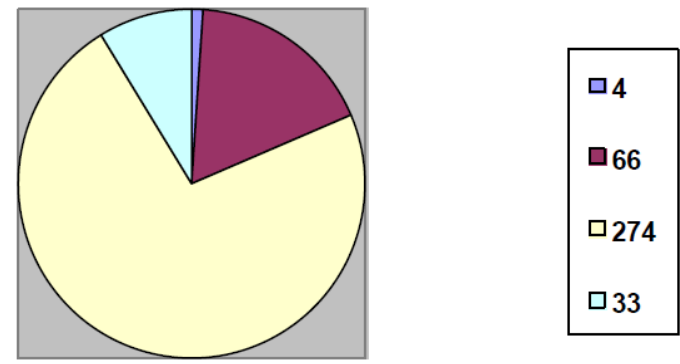

Figure 2: Percentage of each strategy Of Mice and Men

TABLE 5:

TOTAL PERCENTAGE

\begin{tabular}{|l|l|l|}
\hline Strategies & Frequency & Percentage \\
\hline Using an idiom of similar meaning and form & 9 & $2.21 \%$ \\
\hline Using an idiom of similar meaning but dissimilar form & 74 & $18.18 \%$ \\
\hline Translation by paraphrase & 290 & $71.25 \%$ \\
\hline Translation by omission & 34 & $8.35 \%$ \\
\hline Total & 407 & $100 \%$ \\
\hline
\end{tabular}
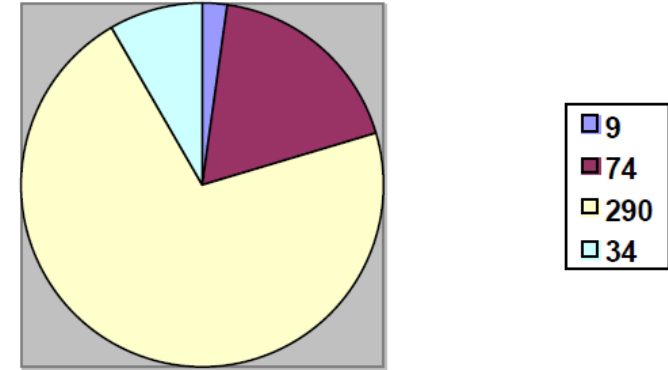

Figure 3: Total percentage

\section{CONCLUSION}

Translation is a difficult task necessary for transferring the concepts and meanings from one language into another. But, some concepts in one language are problematic for the translator to convey into another language. Among these concepts, idioms have a great position especially in novels. Little work has been done on this subject and the researcher tried to do an all-inclusive study on the translation of idioms by Iranian translators. But, no doubt, much work is to be done in future.

The present research was an attempt to investigate the strategies used in English into Persian translation of idioms and idiomatic expressions in novels. As discussed earlier, the researcher decided to work on the idioms which are troublesome in the process of translation, and at the same time, are of great importance in transferring cultural aspects of a language through translation. The research was done based on Baker's strategies for translation of idioms including 4 strategies which were mentioned before.

The high frequency of paraphrasing as a strategy in translating idiomatic expressions in novels stands to show the reluctant sense among translators in finding an equivalent idiom in the TL. This may be due to the fact that they do not have a full command of Persian idiomatic expressions.

Henceforth, because of the high frequency of idioms in English novels, translators need to equip themselves with idioms in Persian, so that the reader does not sense any abnormality in the text, since as found in many occasions in the corpus, many instances of paraphrasing idioms either violate the maxims or fail to raise the original illocutionary meaning.

The results of the study are very useful for novice translators who can adopt more suitable approaches for translating idioms. In fact, strategies used by experienced translators in this regard can guide them through their work of rendering English texts into Persian. 
In addition, translation teachers can use the outcomes of the study to teach translation strategies in their classes in a more practical way. Language learners can also take advantage of the research in order to know English and Persian idioms much better. They can compare and contrast English idioms with their Persian counterparts to become familiar with different cultural aspects of the societies.

During the research what attracted the attention of the researcher was the fact that some parts of the source novels were omitted by the translators. Based on this and other findings of the study, the following suggestions can be made for those who are eager to investigate this area:

a) What are the reasons behind omitting parts of the foreign books translated into Persian, particularly novels?

b) What are the influences of genre and style of writing of the translator or the original author in translating novels?

c) What are the differences between novels translated before and after Islamic revolution in Iran concerning the style of writing and use of words?

This study addressed translation of idioms in novels. Other researches can be administrated considering the translation of other linguistic issues such as slangs, collocations, proverbs, and so on.

\section{REFERENCES}

[1] Abrams, M. H. A (1993.) Glossary of literary terms. 7th edition. Fort Worth: Harcourt Brace College Pub. [Now superseded by later editions.]

[2] Armellino, Elisa. (2003). Translating culture-bound elements in subtitling. Translation Journal. Retrieved July 6, 2010, from http://accurapid.com/journal/44culturebound.htm.

[3] Baker, M. (1992). In other words: A Course book on translation. London and New York: Routledge.

[4] Boers, F. (2000a). Enhancing metaphorical awareness in specialized reading. English for specific purposes, 19: 137-147.

[5] Cain, K. \& Oakhill, J. \& Lemmon, K. (2004). The Relation Between Children's Reading Comprehension Level and Their Comprehension of Idioms. Journal of Experimental Child Psychology, 90, 65-87.

[6] Chang and Fischer. (2006). "Understanding idioms". Retrieved January 22, 2010 from http://www.icsi.berkeley.edu/ nchang/pubs.

[7] Chesterman, A. (2005). 'Bridge Concepts in Translation Studies'. In Wolf, Michaela \& Fukari, Alexandra (eds.): Translation Sociology. A new discipline under construction. Selected papers from the International conference on Translating and Interpreting as a Social Practice, Graz, 5-7 May 2005. Amsterdam \& Philadephia: John Benjamins.

[8] Collis, H. (1994). 101 American English Idioms. Illinois: NTC publishing Group.

[9] Fazly, A. and S. Stevenson. (2006). "Automatically constructing a lexicon of verb phrase idiomatic combinations". Retrieved January 19, 2010 from: http://acl.ldc.upenn.edu/E/E06-1043. pdf.

[10] Fernando, C. (1996). Idioms and Idiomaticity. Oxford: Oxford University Press.

[11] Fernando, C. and Flavell, R. (1981). On Idiom: Critical views and perspectives. Exeter Linguistic Studies 5, University of Exeter. Retrieved on September 9, 2009 from: http://ling.kgw.tuberlin.de/lexicography/data/IDIM.htm.

[12] Ghaffari, S. (2001). A dictionary of idioms Persian-English. Asim, Tehran, Iran.

[13] Lörscher, Wolfgang. (1991). Translation Performance, Translation Process, and Translation Strategies. A Psycholinguistic Investigation. Tübingen: Günter Narr Verlag.

[14] Schowarz, B. (2003). 'Translation in a confined space: Translation Journal, vol. 6, no. 4. Retrieved on February 18, 2009 from: www.accurapid.com/journal/22subtitles.htm

[15] Seidl, J. and W. Mc Mordie. (1988). English Idioms, Oxford: Oxford University Press.

[16] Stock, O. (1989). "Parsing with flexibility, dynamic strategies, and idioms in mind", Computational Linguistics, 15.1.

[17] Venuti, L. (1995). The Translator's Invisibility: a history of translation. Routledge. London.

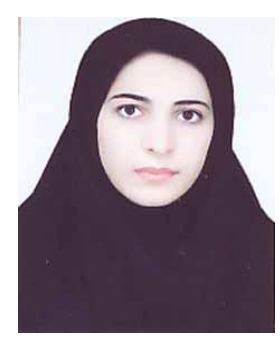

Shokooh Khosravi was born in Shahrekord, Iran in 1985. She received her BA in English Literature from Kashan State University in 2007 and her MA in English Translation from Science and Research Branch, Islamic Azad University, Tehran, Iran in 2011.

She has been working as a freelance translator since 2003 and she is also working as a translator for "World Translators Network" since 2011. She has also worked as a Technical Manager in some Travel Agencies in Shahrekord. She also holds the degree of Tour Leader/Guide from Cultural Heritage, Handicrafts and Tourism Organization. Her main areas of interest are learning idioms, vocabularies, proverbs and literary translation.

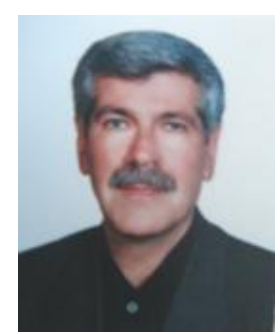

Mohammad Khatib is Assistant Professor of TEFL at Allameh Tabataba'i University. He holds a Ph.D. in TEFL (Allameh Tabataba'i University, 1999), an M. A. and a B. A. in English Literature from Tehran University (1977 and 1972 respectively).

He began teaching at Allameh in 1981 and presently offers graduate and post-graduate courses in SLA Theories, Methodology, Literature in EFL Classes and English Literature. His main areas of interest include SLA Theories, language learning strategies, culture and the integration of language and literature. He has published some articles on TEFL in Iranian Journals of Applied Linguistics. He has translated a book of short stories from famous writers of the world and published a guidebook on Shakespeare's selected sonnets. 